HIV prevention

\section{Peer led HIV prevention among homosexual men in Britain}

\section{J Elford, G Hart, L Sherr, L Williamson, G Bolding}

\section{Expanding the evidence base}

T mention controlled trials and behavioural interventions in the same breath can generate sufficient heat to cause spontaneous combustion. Nowhere is this more evident than in the field of sexual health promotion. But our experience suggests that, for those who can stand the heat, controlled trials can also generate an expanded evidence base for HIV prevention.

Controlled trials conducted in the United States provide persuasive evidence that peer education can bring about a significant reduction in high risk sexual behaviour among homosexual men. For example, peer educators recruited from "gay" bars in small towns made a significant impact upon sexual behaviour at a community level. ${ }^{1-3}$ The proportion of homosexual men who engaged in unprotected anal intercourse (UAI) decreased by about one third following the peer led intervention whereas no change was observed among men using bars in towns without the intervention (controls). The Mpowerment project in California and Oregon also reported a significant reduction in the frequency of unprotected anal intercourse with both regular and casual partners following a peer led intervention. ${ }^{45}$

These peer education programmes drew on a diffusion of innovation model whereby popular opinion leaders engaged in conversation with other homosexual men to promote HIV risk reduction. ${ }^{67}$ According to this model, behaviour change initially adopted and endorsed by the opinion leaders gradually diffuses throughout the population. The model is well suited to community level HIV prevention campaigns that typically require the initiation, diffusion, and long term maintenance of behaviour change. ${ }^{8}$

Encouraging as the North American studies are, however, it cannot be assumed that their findings are directly transferable to the United Kingdom, nor from small towns to large metropolitan areas. None the less, a systematic review undertaken in the mid-1990s of behavioural interventions for HIV prevention found the US research around peer education promising. ${ }^{9}$ The authors of the systematic review recommended that interventions using peer educators be formulated and evaluated in the United Kingdom in methodologically sound trials. In response, two community based trials-one in London the other in Scotland-were developed, quite independently, to determine whether it was possible to transfer this model of peer education from the United States to the United Kingdom.

One of the criteria for methodological soundness laid down by the systematic review was that the interventions should be evaluated by means of a randomised controlled trial. This created enormous controversy. On the one hand it was argued that health promotion interventions should be evaluated with the same degree of rigour as clinical or pharmaceutical interventions by means of randomised controlled trials. On the other hand, it was suggested that this approach would restrict the evaluation to a limited range of outcome measures and ignore the processes that underlie health promotion. Indeed, one of the criticisms levelled against randomised controlled trials is that they fail to provide insight into important qualitative aspects of an intervention such as feasibility, transferability, practical constraints, and cultural adaptation. ${ }^{10}$ Rather than rejecting controlled trials outright, however, we believe a middle way exists which draws on the strengths of both quantitative and qualitative research methodologies. Integrating process evaluation into the design of a controlled trial can generate both outcome data as well as providing insight into important qualitative aspects of the intervention.

In both London and Scotland, peer education programmes were developed between 1997-9 with the aim of reducing the frequency of high risk sexual behaviour among homosexual men and increasing the uptake of HIV testing or sexual health services. They were evaluated by means of controlled trials with outcome and process evaluation running in tandem. ${ }^{112}$

In Scotland, the intervention group comprised homosexual men using bars in Glasgow while the control group was made up of homosexual men using bars in Edinburgh (five exclusively gay bars in each city). There is very little movement of men between the gay scenes of Glasgow and Edinburgh so the cities provided relatively discrete environments where the intervention could be introduced into one city but not the other.

Within central London, five gyms were identified with a large homosexual membership. People tend to go regularly to only one gym so these gyms provided discrete environments where a peer led intervention could be introduced into some but not into others. While it would have been desirable to evaluate a peer led intervention in gay bars in London, it would have been difficult to create distinct intervention and control groups because of the movement of patrons between bars (known as "contamination").

In London and Scotland, the impact of peer education was evaluated by distributing anonymous self administered questionnaires to both the intervention and control groups at baseline and follow up. Detailed information was collected on sexual risk behaviour, HIV testing, or uptake of sexual health services. Both studies came up with identical findings. The peer education programmes had no significant impact on sexual risk behaviour, HIV testing, or service uptake at a community level. ${ }^{13}{ }^{14}$ There were no significant differences between intervention and control groups in the rate of change over time on any of the predetermined outcomes.

\section{Other models of peer education could succeed in Britain}

Why did peer led interventions, shown to be effective in the United States, fail to have any significant impact at a community level on the risk behaviours of homosexual men in London or Glasgow? Process evaluation threw light on this question. ${ }^{75}$ In both studies attrition was an important factor. Recruiting and retaining peer educators proved to be more difficult than originally envisaged. For example, in London, only one in five potential peer educators initially identified remained with the project to the end. Problems in recruiting enough peer educators in Glasgow resulted in people being recruited from local gay organisations and being paid for their time. Peer educators also reported barriers to communication. They found it difficult to talk about sex with complete strangers, although talking about sexual health (for example, where to go for a test) was easier. Interestingly, in London, some of the peer educators said they could imagine the intervention working better in 
small towns rather than a big city, where approaching a stranger may be interpreted as a sexual advance.

An additional factor in London was that the critical mass for diffusion was never established-only 3\% of men surveyed said they had spoken to a peer educator during the intervention period. Rather than peer education not working in London, it simply didn't happen. On the other hand, in Glasgow, nearly a third of homosexual men surveyed said they had spoken to a peer educator. ${ }^{16}$ Yet still no significant community impact was seen when comparing Glasgow with Edinburgh even though intervention effects on HIV testing and hepatitis B vaccination were apparent for men reporting direct contact with peer educators.

These studies demonstrate that it is possible to successfully conduct controlled trials to evaluate behavioural interventions in Britain. By integrating process evaluation into the trial design from the very start we were better able to understand and interpret the outcomes. Conducted independently in London and Scotland, these studies provide us with an expanded evidence base for resource allocation, policy formulation, and planning HIV prevention programmes. It appears that a model of peer education found to be successful in small US towns may not transfer directly to large metropolitan areas in the United Kingdom. Had we not conducted the trials we may still be delivering an intervention that clearly does not work in large cities. However, we should not entirely dismiss the possibility that other models of peer education could succeed in Britain, especially in small towns comparable to the small US towns where the model was first evaluated. There is certainly an urgent need for innovative and effective sexual health promotion programmes in such communities which would address local epidemics of gonorrhoea and syphilis as well as the response to HIV in an age of effective antiretroviral treatments. A nationwide trial evaluating other models of peer led sexual health promotion in small British towns would expand the evidence base further-evidence which could contribute to the development and implementation of the national strategy for sexual health and HIV. ${ }^{17}$

Sex Transm Infect 2002;78: 158-159

\section{Authors' affiliations}

J Elford, G Bolding, Institute of Health Sciences and St Bartholomew School of Nursing and Midwifery, City University, London, UK

G Hart, L Williamson, MRC Social and Public Health Sciences Research Unit, University of Glasgow, UK

L Sherr, Royal Free and University College Medical School, University College London, UK

Correspondence to: Professor Jonathan Elford, City University, Institute of Health Sciences, St Bartholomew School of Nursing and Midwifery, 20 Bartholomew Close, London ECIA 7QN,

UK; i.elford@city.ac.uk

\section{REFERENCES}

1 Kelly JA, Murphy DA, Sikkema KJ, et al Randomised, controlled, community-level HIV-prevention intervention for sexual-risk behaviour among homosexual men in US cities. Community HIV Prevention Research Collaborative. Lancet 1997;350:1500-5.

2 Kelly JA, St Lawrence JS, Stevenson LY, et al. Community AIDS/HIV risk reduction: the effects of endorsements by popular people in three cities. Am J Public Health 1992;82:1483-9.

3 Kelly JA, St Lawrence JS, Diaz YE, et al. HIV risk behavior reduction following intervention with key opinion leaders of population: an experimental analysis. Am J Public Health 1991:81:168-71.

4 Kegeles SM, Hays RB, Pollack LM, et al. Mobilizing young gay and bisexual men for HIV prevention: a two-community study. AIDS 1999;13:1753-62.

5 Kegeles SM, Hays RB, Coates TJ. The Mpowerment Project: a community-level HIV Mpowerment Project: a community-level HIV Am J Public Health 1996;86:1129-36.

6 Rogers E. Diffusion of innovations. New York: Free Press, 1983

7 Hart GJ. Peer education and community based HIV prevention for homosexual men: peer led, evidence based, or fashion driven? Sex Transm Infect 1998;74:87-9.

8 Kelly JA. HIV prevention among gay and bisexual men in small cities. In: DiClemente RJ, Peterson JL, eds. Preventing AIDS. Theories and methods of behavioural interventions. New York: Plenum Press, 1994:297-317.

9 Holland, J, Arnold, S Fullerton D, et al. Review of effectiveness of health promotion interventions for men who have sex with men. interventions for men who have sex with men. London: Social Science Research Unit, Institute of Education, 1994

10 Van de Ven P, Aggleton P. What constitutes evidence in HIV/AIDS education? Health Educ Res 1999;14:461-71.

11 Elford J, Sherr L, Bolding G, et al. Peer-led HIV prevention among gay men in London (the 4 gym project). Intervention and (the 4 gym project). Intervention and
evaluation. In: Watson J, Platt S, eds. Researching health promotion. London: Researching health
Routledge, 2000

12 Flowers P, Frankis JS, Hart GJ. Evidence and the evaluation of a community-leve intervention: researching the Gay Men's Task Force Initiative. In: Watson J, Platt S, eds. Researching health promotion. Edinburgh: Routledge, 2000.

13 Elford J, Bolding G, Sherr L. Peer education has no significant impact on HIV risk behaviours among gay men in London. AIDS $2001 ; 15: 535-8$

14 Flowers $\mathbf{P}$, Hart G, Williamson L, et al. Does bar-based, peer-led sexual health promotion have a community-level effect among gay men in Scotland? Int J STD AIDS 2002;13:102-8.

15 Elford J, Sherr L, Bolding G, et al. Peer-led HIV prevention among gay men in London: process evaluation. AIDS Care 2002; 14:352-60.

16 Williamson L, Hart G, Flowers $P$, et al. The Gay Men's Task Force: the impact of peer education on the sexual health behaviour of homosexual men in Glasgow. Sex Transm Infect 2001;77:427-32

17 Department of Health. The national strategy for sexual health and HIV. London: $\mathrm{DoH}$ 2001. 